\title{
O presente e o futuro das pesquisas em Educação e de sua divulgação
}

\author{
Cláudia Valentina Assumpção Galian'1 \\ ORCID: 0000-0002-1924-8802 \\ Emerson de Pietri ${ }^{1}$ \\ ORCID: 0000-0001-5060-9891 \\ Bianca Salazar Guizzo ${ }^{2 \star}$ \\ ORCID:0000-0003-1080-2210 \\ Fabiana de Amorim Marcello $0^{3 *}$ \\ ORCID: 0000-0001-9720-2650 \\ Fernanda Müller ${ }^{*}$ \\ ORCID: 0000-0002-1788-8662
}

Iniciamos e concluímos 2020 sem uma solução para a maior crise sanitária dos últimos 100 anos. A pandemia do COVID-19, tal como um fato social total (MAUSS, 2017; RIBEIRO, 2020), não se reduziu somente a um problema de saúde pública, mas pôs radicalmente em movimento a totalidade da sociedade e de suas instituições. Mais de seis milhões de brasileiros/as contraíram a doença, sendo que desses, 160 mil foram vítimas fatais - e isso até o momento (novembro de 2020). Escolas públicas e privadas em todo o país fecharam as portas em março e umas poucas reabriram recentemente, seguindo novos protocolos. A pandemia escancarou desigualdades sociais antigas e introduziu outras. Nem a quarentena, o direito de se reservar e de se proteger, foi possivel para todos. Tampouco o de se despedir dos entes queridos.

A pandemia catalisa um contexto político em crise e polarizado. Aos olhos de boa parte da nossa comunidade - surpreendentemente não da sua totalidade - é

1- Editores de Educação e Pesquisa. Universidade de São Paulo, São Paulo, SP, Brasil.

* Organizadoras da Seção temática "Infância, Política e Educação".

2- Universidade Luterana do Brasil, Canoas, Rio Grande do Sul, Brasil. Contato: bianca.guizzo@gmail.com. Professora Adjunta da Universidade Luterana do Brasil, onde atua no Curso de Pedagogia e no Programa de Pós-Graduação em Educação.

3- Universidade Federal do Rio Grande do Sul, Porto Alegre, Rio Grande do Sul, Brasil. Contato:famarcello@gmail.com. Professora Adjunta da Universidade Federal do Rio Grande do Sul, onde coordena o Grupo de Pesquisa sobre Infâncias (GEIN). Professora do Programa de Pós-Graduação em Educação da UFRGS e Bolsista de Produtividade em Pesquisa do CNPq.

4- Universidade de Brasilia, Brasília, Distrito Federal, Brasil. Contato: fernandamuller@unb.br. Professora Associada da Universidade de Brasília, onde coordena 0 Grupo Interdisciplinar de Pesquisa sobre a Infância (GIPI). Professora do Programa de Pós-Graduação em Educação da UFMG. 
inadmissivel, talvez insuportável, assistir às queimadas na Amazônia e no Pantanal, problema que tem ao longo dos anos posto em risco a preservação de nossos biomas e povos originários. Para além disso, a insistência no uso de medicamentos não comprovados para o tratamento da COVID-19, a negação da eficácia de uma vacina, os ataques insistentes à democracia e às universidade públicas configuram o absurdo e o espetáculo que prevalecem.

De novo, ela, a pandemia, provoca-nos a pensar a respeito do campo da educação, da escola e das novas desigualdades relacionadas às condições de acesso ao conhecimento. Crianças e adolescentes de nosso país mal se encontraram com seus pares em 2020, ao menos em suas escolas. Pouco interagiram com seus/suas professor/as. Tiveram de abruptamente aprender a aprender e a se relacionar de outras formas, enfrentando o desafio de desenvolverem em casa aprendizagens próprias da escola, sem os apoios usualmente presentes nessa instituição, dos profissionais da educação. Ainda pouco sabemos sobre os impactos de tudo isso na vida de todas as pessoas e de nossa sociedade.

Justamente neste ano, de 2020, completam-se 30 anos da promulgação do Estatuto da Criança e do Adolescente (ECA). 0 volume 46 incorpora a Seção Temática "Infância, Politica e Educação", considerando o ECA em sua relação mais ampliada no contexto da política e das políticas 5 . Igualmente, explora as garantias, as conquistas, e - por que não?-, novas discussões sobre os direitos das crianças. Não esqueçamos que até as imagens produzidas sobre as crianças no decorrer dos meses de pandemia revelam as polarizações na sociedade: de um lado, a invisibilidade (só aos poucos as pesquisas nos têm informado sobre as emoções, as expectativas e as condições de vida das crianças), e, de outro, a exposição perturbadora, sem máscaras nem proteção, por vezes em roupas militares e dedos em riste. Seguem, também elas, em um clima político de incertezas e polarizações que está instalado no país.

As crianças e a infância são focalizadas pelo ECA de uma forma inédita na história da legislação brasileira. Todavia, a pandemia insistentemente convoca-nos à reflexão sobre as "consequências para a infância de todos os tipos de política”. (QVORTRUP, 2010, p. 785).

A Seção Temática ganha relevância e potência ao garantir um espaço de discussão sobre política e políticas. Mais além, joga luz sobre experiências, resistências e ações de crianças que vivem em um mundo onde nós, adultos, chegamos primeiro. Se Qvortrup (2010) expôs um triplo retrato discursivo acerca

\footnotetext{
5- Qvortrup (2010, p. 787) sugere a diferença entre política, no singular, e políticas. A primeira se situaria nas "decisões sobre a estrutura da infância, sobre o lugar da infância em uma sociedade dominada por adultos"; já as políticas seriam as "iniciativas nacionais de longo prazo voltadas ao desenvolvimento das crianças como grupo". Seguindo esta definição, o ECA seria parte das políticas, no plural, ainda que afete a política da infância pelo simples fato de concebê-la como sujeito de direitos.
} 
das crianças no mundo contemporâneo - são sentimentais, irracionais e separadas do mundo adulto -, mesmo considerando as possíveis ambiguidades decorrentes daí, o foco volta-se aqui para o lugar que a criança assume na sociedade contemporânea, nesse mundo, com seus pares e com os adultos. Porque as crianças não são alienadas das relações nem com o mundo nem com outros grupos geracionais, temos muito a discutir sobre "Infância, Política e Educação".

Outra marca do ano 2020 foram os acontecimentos relacionados a crimes raciais, no Brasil e em outros países - infelizmente constituindo uma realidade insistente e duradoura -, que se apresentam como desafios sociais e políticos principalmente para as Ciências Humanas. Nesse sentido, Educação e Pesquisa publica em seu volume 46 a tradução do artigo de Judith Butler (2020) a respeito do racismo e os efeitos que produz social e culturalmente, os quais se constituem de modo muitas vezes não evidente, dado que resultantes de uma episteme racista. 0 campo educacional ocupa posição fundamental para a construção de um futuro mais justo e democrático, pelo caráter formativo que lhe é inerente.

\section{Ciência aberta: os desafios para os processos editoriais}

No ano de 2020, as propostas do SciELO para a promoção da ciência aberta avançaram e se apresentaram aos periódicos científicos como desafios que demandam reflexão e discussões quanto às práticas editoriais e às relações com a divulgação dos resultados de pesquisa e à impessoalidade dos processos de avaliação. Essas ações constituem, portanto, muito mais do que exigências voltadas à adequação de práticas e não podem deixar de ser objeto de análise criteriosa, que não perca de vista a especificidade dos campos de produção do conhecimento.

Nesse sentido, a Revista Educação e Pesquisa foi convidada a participar do Encontro Anual do SciELO, no final do ano de 2019, compondo o painel realizado no evento para a discussão sobre as possibilidades da ciência aberta. Nessa oportunidade, foram levados para o debate argumentos produzidos pela Comissão Editorial do periódico a respeito dos temas em discussão.

Observou-se que pode configurar risco para pesquisadores/as, editores/as e outros sujeitos da pesquisa, a disponibilização de dados que remetam a temas polêmicos (como os relacionados a questões de raça, gênero ou a referenciais teóricos que sofram perseguição ideológica - como se tem visto recentemente no país). A preocupação explica-se pela constatação das marcas, do contexto atual, de retrocessos sociais, políticos, econômicos e culturais no Brasil.

Além disso, a abertura de dados, em pesquisas de caráter descritivista/interpretativista, poderia representar prejuízo a um/a pesquisador/a que tenha encontrado 
uma abordagem original de um determinado tema ou objeto de investigação: conceder acesso ao material de análise pode representar a perda da originalidade nos trabalhos que esse/a pesquisador/a venha a desenvolver. É preciso considerar também que a disponibilização de dados em pesquisas de caráter descritivista/interpretativista é uma prática por vezes difícil de se realizar, uma vez que a produção dos dados é resultante de um processo discursivo que se materializa na e com a própria construção textual. Assim, não é possível isolar o dado do processo discursivo em que ele se constitui: o material de análise, nele mesmo, não se realiza enquanto tal a não ser com o atravessamento teórico-metodológico operado pelo/a analista.

A organização e manutenção de dados, métodos de análise, registros de programas, e de outros materiais de pesquisa, pressupõem custos de operacionalização, o que pode se colocar como um fator de dificuldade para as revistas que já se encontram em condições financeiras difíceis, tanto em razão de porventura haver a necessidade de arcar com os custos do armazenamento, quanto pelo acréscimo de trabalho que essa tarefa produz para quem realiza as atividades de gerenciamento do periódico.

A respeito dos preprints, raciocínio similar pode ser produzido ao que se fez em relação à disponibilização do acesso a dados e materiais de pesquisa: em pesquisas de caráter descritivista/interpretativista, as intervenções de leitores recaem sobre o próprio trabalho autoral, uma vez que a produção e análise dos dados, independentemente da origem do material de pesquisa, se constitui em operações discursivas efetuadas pelo analista. Nesse sentido, a publicização prévia de ideias e argumentos pode ensejar sua reprodução, o que pode resultar, por sua apropriação por outros/as pesquisadores/as, em perda da originalidade da abordagem ou dos resultados, ou, no limite, em plágio. A realização das atividades para a disponibilização e desenvolvimento de processos de preprint pressupõe custos de operacionalização, o que também pode se colocar como um fator de dificuldade para as revistas com as estruturas de funcionamento e a equipe que possuem para gerir e realizar suas atividades editoriais.

A abertura dos mecanismos de avaliação, requerida pelas práticas editoriais referenciadas em preprints, também pela avaliação de manuscrito aberta por pares, é proposta como possibilidade de garantir mais transparência ao processo. Porém, essa abertura leva à perda da impessoalidade, o que pode levar à impossibilidade de isenção, a constrangimento ou à efetiva intimidação, em razão das relações dissimétricas que a produção e análise se constituem nas práticas científicas em seus diversos âmbitos institucionais. Possivelmente, nessa dinâmica, emitir um parecer pode se tornar uma atividade pouco 
convidativa, porque, além de trabalhosa, pode ser geradora de incômodos e/ou estigmas nas trajetórias dos profissionais atuantes no campo da educação, a depender das diferentes posições que ocupam esses sujeitos - para os periódicos científicos, que já encontram dificuldades para conseguirem pareceres, isso pode configurar um problema adicional.

Considera-se que as propostas relativas a tornar as práticas editoriais mais acessíveis em seus modos de funcionamento representam valorosa contribuição à produção do conhecimento; porém, é preciso ponderar também a respeito das condições em que as mudanças nas práticas e sua abertura se realizam, de modo a observar não apenas o que seja próprio da cultura científica e da produção do conhecimento, mas também as condições sociais, políticas e econômicas em que essa cultura se constitui.

\section{Os impactos das políticas de financiamento da ciência para os processos editoriais}

Foram muitos desafios de diversas ordens enfrentados neste ano de 2020 - sanitários, científicos, sociais, políticos e econômicos - em decorrência da pandemia de COVID-19, mas, antes e concomitantemente a ela, em razão da destruição das políticas públicas voltadas à preservação das condições de vida da população em suas diferentes necessidades: trabalhistas, previdenciárias, educacionais e científicas. Nesse último caso, observou-se a redução do investimento federal em produção de ciência e sua divulgação, mais acentuadamente para as Ciências Humanas.

Os programas de auxílio à editoração deixaram a quase totalidade dos periódicos em Educação sem financiamento para a realização de suas atividades. A supressão das políticas de auxílio à divulgação científica prejudicou o trabalho das comissões editoriais e representa uma das faces do retrocesso imposto à ciência no país.

Em condições desfavoráveis de gestão e funcionamento, os periódicos brasileiros do campo educacional têm alterado também seus modos de classificação em decorrência das novas regras de avaliação do Qualis periódicos anunciadas pela CAPES. Representava já objeto de muita preocupação a utilização de métricas produzidas por empresas como Elsevier, Clarivate Analytics e Google como critério primeiro de avaliação.

0 recurso para que os periódicos brasileiros da área não fossem expropriados em suas produções pela lógica comercial das empresas de indexação foi a definição de subáreas que preservassem as publicações nacionais de serem integradas aos conjuntos de revistas estrangeiras pertencentes a essas bases e publicadas em inglês. Com isso, a aposta era a de que 
seriam respeitadas as especificidades da produção educacional científica brasileira, de modo a comparar suas métricas no interior da cultura acadêmica em que se constituem. Entretanto, até o momento em que este editorial está sendo escrito, permanece a decisão unilateral da CAPES de não respeitar o acordo estabelecido com o colégio de Humanidades para que as revistas fossem dispostas em subáreas definidas por região de origem e idioma. Impõem-se, assim, a lógica empresarial e o interesse dos grupos econômicos internacionais definindo as políticas públicas para a ciência no Brasil e colocando-as no interior de suas estratégias de mercado.

\section{Preservar a memória para cuidar do futuro}

Além da edição de artigos, Educação e Pesquisa tem publicado documentos resultantes de trabalhos de tradução de textos de relevância para o campo educacional, além de entrevistas com pesquisadores a respeito de sua contribuição para a produção do conhecimento em Educação. Desse modo, busca-se preservar a memória do campo, revisitado em bases documentais ou com o depoimento de pesquisadores/as a respeito dos conhecimentos que ajudaram a produzir.

Nesse sentido, além do artigo de Judith Butler, anteriormente mencionado, outras duas traduções foram publicadas neste ano de 2020 por Educação e Pesquisa. A conferência Contexte scientifique de la recherche sur l'édition scolaire au plan local, national e mondial foi apresentada no dia 5 de novembro de 2007, pelo prof. Dr. Alain Choppin, na Abertura do Simpósio Internacional Livro Didático: Educação e História, no auditório da Faculdade de Educação de São Paulo. Trata-se de um importante texto que apresenta um mapeamento rigoroso das pesquisas em torno dos livros didáticos no mundo ao longo do tempo, ressaltando os movimentos no campo, as contribuições para a educação e a potência dos caminhos de pesquisa que vão se constituindo em diferentes países em torno desses documentos.

A tradução de The transnational in the history of education, texto de autoria de Eugenia Roldán Vera e Eckhardt Fuchs, que compõe o capítulo introdutório da obra de mesmo título organizada pelas autoras, reconstitui a formação histórica desse campo de conhecimentos, evidenciando seus motivos iniciais, relacionados à perspectiva de construção de uma educação pela paz no contexto do pós-guerra mundial, às suas relações críticas com o processo de globalização e os efeitos que esse processo produz em dimensões diversas, da política à econômica, com os sentidos e significados que podem ser construídos para a compreensão e interpretação do que seja historicamente o transnacional em termos educacionais. 
0 registro da memória histórica e suas relações com o momento presente também se concretiza nas entrevistas Um intelectual cosmopolita: trajetórias de Noah Sobe na (história da) educação, em que são discutidas as relações entre história e produção do futuro, e Perspectivas da pesquisa em educação e em didática das línguas na Universidade de Genebra, em que a Professora Ecaterina Bulea Bronckart dialoga a respeito do processo histórico de elaboração do Interacionismo Sociodiscursivo e de seus desafıos atuais.

Seguem os periódicos científicos e os/as pesquisadores/as da educação na luta pela valorização e pelo respeito às especificidades do campo, de modo que novas exigências e critérios sejam efetivamente discutidos e implementados em acordo com os compromissos assumidos com a comunidade científica. Trata-se de uma luta inescapável já que as políticas para a ciência promovidas pelo atual governo do país representam ataque sem precedentes à autonomia acadêmica brasileira.

\section{Referências}

BUTLER, Judith. Endangered/endangering: achematic racism and white paranoia. In: GOODING-WILLIAMS, Robert (ed.) Reading rodney king/reading urban uprising. London: New York: Routledge, 1993. p. 15-22.

MAUSS, Marcel. Sociologia e Antropologia. São Paulo: UBU, 2017. Publicado originalmente em 1950.

QVORTRUP, Jens. Infância e política. Cadernos de Pesquisa, São Paulo, v. 40, n. 141, p. 777792, dez. 2010. Disponível em: http://www.SciELO.br/SciELO.php?script=sci_arttext\&pid=S010015742010000300006\&lng=en\&nrm=iso. Acesso em: 27 out. 2020. http://dx.doi.org/10.1590/S010015742010000300006 .

RIBEIRO, Gustavo Lins. Cientistas sociais e o coronavírus: medo global. Boletim Cientistas Sociais, São Paulo, n. 5, p. 1-4, 2020. Disponivel em: http://anpocs.org/index.php/publicacoes-sp-2056165036/ boletim-cientistas-sociais/2311-boletim-n-3-as-ciencias-sociais-e-a-saude-coletiva-frente-a-atualepidemia-de-ignorancia-irresponsabilidade-e-ma-fe-3. Acesso em: 29 out. 2020. 